\title{
Conhecimento de estudantes de 9 a 12 anos do CEF GAN, Asa Nor- te-DF, sobre trauma dental, após atividade educativa
}

Larissa Ribeiro Silva1, Isabela Fernandes Ferreira², Paulo Sedlaceck ${ }^{3}$, Fernanda Cristina Pimentel Garcia ${ }^{4}$ Adriano de Almeida Lima4, Liliana Vicente Melo de Lucas Rezende ${ }^{4}$.

${ }^{1}$ Aluna de Mestrado em Odontologia da Universidade de Brasília. ${ }^{2}$ Cirurgiã-dentista. ${ }^{3}$ Cirurgião-dentista do CAOE - UNESP Araçatuba. ${ }^{4}$ Professor Adjunto da Universidade de Brasília (UnB).

\section{Resumo}

Introdução: O traumatismo dentário encontra-se entre os principais agravos de saúde bucal em todo o mundo, juntamente com a doença cárie e o câncer bucal. Dentre todas as lesões causadas, a avulsão dental é a mais crítica, pois ocorre o deslocamento completo do dente do seu alvéolo de origem e o sucesso do tratamento mostra-se vinculado à vários fatores, tais como período extra alveolar, meio de armazenamento do dente e o tipo de reimplante. A disseminação do conhecimento, entre as populações alvo, é um meio de se prevenir os traumas dentários e minimizar suas consequências. Objetivo: Avaliar o conhecimento dos estudantes do ensino fundamental sobre trauma dental. Metodologia: Assim, foi avaliado o conhecimento sobre avulsão e reimplante dentários de estudantes com idade entre 9 a 12 anos, por meio de um questionário. Em seguida, os estudantes participaram de uma atividade educativa (jogo da memória) sobre o tema e, após, responderam o questionário novamente. Resultados: Observou-se, a partir de uma análise descritiva, que os resultados foram mais favoráveis às respostas depois da atividade educativa apresentando mais acertos $(M=60,45 ; D P=14,92)$ em comparação às respostas obtidas antes da mesma $(M=50,68 ; D P=11,06)$. Conclusão: Os resultados obtidos permitiram concluir que as atividades educativas com estudantes de 9 a 12 anos de idade são necessárias e permitem aumentar o nível de conhecimento sobre avulsão e reimplantes dentários.

Palavras-chave: Trauma dental; Avulsão dentária; Reimplante dentário; Criança; Questionários.

\section{Introdução}

O traumatismo dentário é um problema comum na Odontologia e pode influenciar negativamente a qualidade de vida das pessoas. Encontra-se entre os principais agravos de saúde bucal em todo o mundo, juntamente com a doença cárie e o câncer bucal ${ }^{1}$.

Acontece frequentemente na infância e adolescência, seja durante a prática de esportes ou em acidentes, podendo ocasionar perdas dentais irreparáveis em alguns casos, tanto no momento do ocorrido como anos após². Entretanto, as crianças não estão sozinhas nesse quadro, os homens adultos também classificam a etiologia do trauma, pois a prática de atividades físicas radicais e agressivas tem aumentando significativamente, e junto com os acidentes automobilísticos, contribuem para que o trauma seja considerado um problema crescente de saúde pública ${ }^{3}$.

Os acidentes envolvendo os dentes são muito frequentes, podendo acontecer apenas uma fratura de esmalte, até o completo deslocamento do dente de seu alvéolo, caracterizando o quadro mais preocupante $^{4}$. Esse tipo de injúria, acomete principalmente os dentes anteriores permanentes do arco superior ${ }^{3,5}$ e cerca de $16 \%$ das crianças em idade escolar já experimentaram a avulsão dentária ${ }^{6}$. Como a maioria da população não conhece o protocolo para um correto reposicionamento do dente, muitos estudos vêm sendo realizados, com o intuito de disseminar o conhecimento sobre reimplantes, contribuindo para a melhora do prognóstico do dente afetado.

A maioria dos pacientes busca ajuda do dentista tardiamente e sem armazenar o dente de forma adequada. Esse fato decorre da não orientação do paciente diante do trauma, e pesquisas mostram que, para se manter um metabolismo celular satisfatório, as substâncias devem ser repostas de 60 a 120 minutos após o acidente ${ }^{7}$. Após 5 minutos o processo de reabsorção pós-reimplante começa a se mostra mais significante ${ }^{8}$ sendo que, quanto mais rápido o elemento voltar ao seu alvéolo, maiores são as possibilidades de sucesso ${ }^{9}$, por isso a necessidade de se transmitir a informação sobre esse assunto, nos ambientes escolares, onde se encontra grande parte do público alvo. Segundo Subramaniam et al. ${ }^{10}$, a avulsão dentária representa 0.5 à 16\% das lesões traumáticas na dentição permanente, ocorrendo com mais frequência em pacientes de 7 a 9 anos de idade. O maior índice de acidentes na dentição permanente acontece em crianças do sexo masculino, sendo que a maioria ocorre durante atividades desportivas e recreativas, quedas e acidentes ${ }^{3}$.

Dentre as lesões causadas pelo traumatismo dentário, a avulsão é a mais crítica, pois se trata do deslocamento completo do dente do seu alvéolo de origem, comprometendo a estrutura periodontal, e o suprimento nervoso e sanguíneo ${ }^{11}$. O sucesso desse procedimento mostra-se diretamente dependente de vários fatores, tais como o período extra- alveolar, o meio de armazenamento do dente, o tipo de reimplante e de contenção empregados, tempo de intervenção endodôntica, tipo de medicamento prescrito, higiene oral, bem como a saúde geral do paciente ${ }^{12}$.

O tratamento imediato da avulsão é o reimplante, mas a maioria da população não conhece os protocolos necessários para que isso ocorra e são essas medidas iniciais que ditarão um bom prognóstico, por isso, uma das melhores formas de prevenção das sequelas dessa intercorrência é a disseminação do conhecimento ${ }^{13,14}$. 
Em seu trabalho, Al-Asfour et al. ${ }^{15}$ realizaram uma curta palestra sobre avulsão dentária e averiguaram o nível do conhecimento adquirido. Foi observado que a campanha educativa sobre reimplante melhorou de $8 \%$ para $93 \%$, sobre a avulsão de dentes permanentes. Já em relação à importância do adequado armazenamento do dente avulsionado, subiu de $4 \%$ para $86 \%$.

No estudo desenvolvido por Grewal et al. ${ }^{16}$ também demonstraram uma diferença significativa do conhecimento de diferentes segmentos escolaes (pais, professores e crianças) após instruções de manejo de dentes traumatizados, reforçando a importância de campanhas de conscientização.

Em vista disso, o presente trabalho se justifica pela importância de promover a consciência pública e educar a população que está sujeita ao risco de traumatismo dental e implicará no sucesso do tratamento. Faz-se então, necessário avaliar o conhecimento dos estudantes do ensino fundamental sobre trauma dental, assim como realizar ações educativas sobre avulsão e reimplante dentários, ensinando-os o protocolo que se inicia no momento do trauma até seu tratamento específico.

\section{Material e métodos}

O presente trabalho foi submetido ao Comitê de Ética em Pesquisa da Faculdade de Ciências da Saúde da Universidade de Brasília. Trata-se de uma pesquisa quantitativa exploratória.

A amostra foi aleatoriamente selecionada a partir da população de estudantes do ensino fundamental da rede pública CEF GAN da Asa Norte - D.F, com idade entre 9 e 12 anos. O critério de inclusão dos sujeitos foi o de estarem regularmente matriculados na escola e sua participação no estudo foi voluntária e a confidencialidade dos dados assegurada através de Termo de Consentimento Livre e Esclarecido, que foi assinado pelos pais e/ou responsáveis.

Foi aplicado um questionário específico (Figura 1), elaborado e validado por Castilho et al. ${ }^{17}$, com questões relacionadas à experiência pessoal, conhecimento geral sobre traumatismos dentários e situações envolvendo casos de avulsão e reimplante dentários. Após, os estudantes participaram de uma atividade lúdica: foram divididos em 10 grupos contendo quatro participantes. Cada grupo recebeu um jogo da memória (Figura 2), ilustrado com informações sobre avulsão dental e os procedimentos corretos que devem ser realizados até o reimplante.

Logo após a atividade recreativa, os estudantes responderam novamente o questionário, a fim de se avaliar o conhecimento adquirido sobre o tema. As questões mais significativas tiveram suas respostas reduzidas a inadequada, adequada e não respondidas.

\section{Resultados}

Um total de 40 estudantes de 9 a 12 anos respondeu ao questionário, sendo que a maioria era do gênero masculino $(n=24)(60 \%)$, apresentando idade entre 11 e 12 anos, o que representa 59,18\% das crianças.

Em se tratando da questão sobre as atividades esportivas, grande parte dos alunos (95\%) respondeu praticar algum esporte físico, sendo que os mais realizados são educação física (32,05\%) e futebol (24,35\%). Sobre o que os alunos entendiam por trauma dental, $25 \%(n=10)$ dos alunos marcaram a resposta correta, que seria "uma batida violenta no dente", 20 alunos (50\%) marcaram as alternativas consideradas inadequadas, $22,5 \%(n=9)$ assinalaram a alternativa "não sei", e apenas 1 questionário não havia resposta sobre essa pergunta (2,5\%), antes do jogo da memória. Os questionários respondidos depois do jogo tiveram melhores resultados em relação à alternativa certa $(n=15,37,5 \%)$. Os alunos que apontaram as demais opções foram um total de $17(42,5 \%)$. Apenas 2,5\% $(n=1)$ não responderam à essa questão e $7(17,5 \%)$ optaram pela opção "não sei".

A porcentagem de respostas certas obtidas nos questionários antes e após o jogo da memória, sobre os procedimentos necessários em casos de avulsão, pode ser visualizada no Gráfico I.

\section{GRÁFICO I}

Gráfico II, a seguir, mostra a relação entre os dados obtidos nos questionários antes e depois do jogo da memória, com relação ao meio de conservação do dente avulsionado.

\section{GRÁFICO II}

Sobre o tempo ideal que o dente deve permanecer fora da boca até o reimplante, antes do jogo da memória, apenas $25 \%(n=10)$ dos estudantes responderam que o dente deve ser reposicionado imediatamente após o trauma, $45 \%(n=18)$ não sabiam responder à pergunta, $11(27,5 \%)$ alunos optaram por outras alternativas e apenas 1 (2,5\%) não respondeu. Após a atividade educativa, a opção de reimplante imediato foi escolhida por $32,5 \%(n=13), 35 \%(n=14)$ marcaram outras opções e os que não sabiam responder somaram $32,5 \%(n=13)$.

Quanto ao reposicionamento do dente, ele pode ser feito por quem: $77,5 \%(n=31)$ das crianças responderam que apenas o dentista pode efetuar essa ação. Os questionários respondidos depois do jogo da memória, obtiveram $65 \%$ das respostas "somente o dentista". Nos questionários respondidos antes do jogo, apenas 2 (5\%) tiveram a opção "qualquer pessoa pode reimplantá-lo", esse número aumentou para 12 (30\%), em relação aos alunos que marcaram esta opção correta.

\section{Discussão}

A realização do jogo da memória ajudou a fixar o conhecimento prévio dos alunos sobre trauma dentário, quais atitudes devem-se tomar diante uma avulsão, qual o recipiente mais acessível para manter o dente nessas situações, o tempo máximo que o elemento dentário pode ficar fora de seu alvéolo, e por 


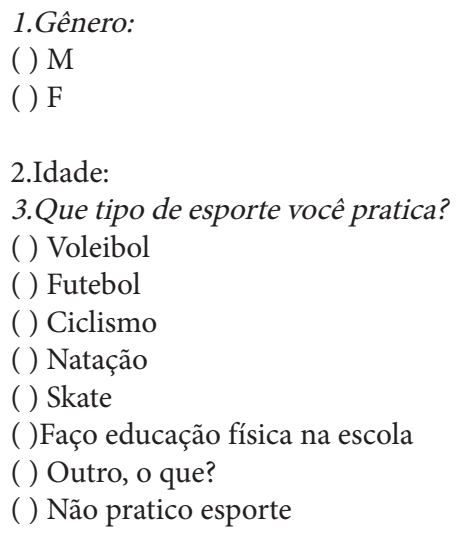

4.Se você sofrer uma queda, machucar sua boca e um de seus dentes cair fora da boca o que você faria?

( ) Voltaria chorando para casa.

( ) Pegaria o dente e o levaria para casa.

( ) Pegaria o dente sujo e o colocaria de volta ao seu lugar na boca.

( ) Pegaria o dente, procuraria uma torneira, o lavaria e o colocaria de volta ao seu lugar na boca e voltaria para casa.

( ) Pegaria o dente procuraria uma torneira, o lavaria e o colocaria de volta ao seu lugar e procuraria um dentista.

( ) Pegaria o dente e procuraria imediatamente um dentista.

5.O que você entende por trauma no dente?

( )Cárie no dente.

( ) Uma batida violenta no dente.

( ) Dor de dente.

( ) Aparelho no dente.

( ) Chupar o dedo.

( ) Ir ao dentista.

( ) Não sei.

6.Escolha as alternativas que representam risco para o seu dente permanente:

( )Dormir

( )Sofrer acidente de carro, moto, bicicleta

()Andar

( )Correr

( )Brigar, lutar

( ) Nadar

( )Nenhuma das respostas acima

7. Você já sofreu batida no dente?

( ) $\mathrm{Sim}$

( ) Não

8. Você já ouviu falar sobre dente que sofreu batida e caiu fora da boca?

( ) $\mathrm{Sim}$

( ) Não

9.Escolha a situação de mais alto risco para seu dente permanente:

( ) Dormir

( ) Sofrer acidente de carro, moto ou bicicleta

( ) Comer

( ) Andar

( ) Correr

( ) Brigar, lutar

( ) Nadar

( ) Nenhuma das respostas acima

Figura 1 - Questionário elaborado e validado por Castilho et al. (2009). (Parte I) 
10. Como se chama a parte do dente que você pode ver no espelho?

( ) Coroa

( ) Raiz

( ) Não sei

11. Uma vez que o dente permanente está fora da boca, o que podemos fazer? Podemos:

( ) Jogá-lo fora porque não tem mais serventia.

( ) Lavá-lo e coloca-lo de volta ao seu lugar.

( ) Entregá-lo para nossa mãe e guardá-lo

( ) Entregá-lo ao dentista mais próximo

( ) Não fazer nada

12. Se o dente permanente cair no chão sujo, o que vocês fazem? Quais das respostas estão corretas? Podemos:

( ) Jogá-lo fora porque não tem mais serventia.

( ) Lavá-lo e coloca-lo de volta no seu lugar

( ) Escovar o dente.

( ) Procurar um dentista.

( ) Não sei.

13. Onde podemos manter o dente permanente no caso dele não ter sido colocado de volta ao seu lugar?

( ) Embrulhado em um papel.

( ) Em um recipiente contendo água da torneira.

( ) Em um recipiente contendo soro fisiológico.

( ) Dentro do bolso.

( ) Em um recipiente contendo leite.

( ) Em um recipiente contendo álcool.

( ) Outro. Qual?

14. Em sua opinião, qual o tempo ideal para que o dente permanente permaneça fora da boca antes de ser colocado de volta ao seu lugar?

( ) Deve ser colocado de volta imediatamente.

( ) $30 \mathrm{~min}$.

( ) 1 hora.

( ) 6 horas.

( ) 24 horas.

( ) Não sei.

15. O dente permanente pode ser colocado novamente de volta em sua boca:

( ) Somente pelo dentista

( ) Por qualquer pessoa

( ) Por ninguém porque o dente está inutilizado

16. Porque é importante saber sobre este assunto?

( ) Porque pode acontecer comigo e assim posso salvar meu dente.

( ) Porque disseram que é importante.

( ) Porque pode representar alguma ajuda para alguém.

( ) Eu não acho que seja importante.

( ) É importante apenas para o dentista.

17. Quando você está praticando atividades físicas você acha que pode quebrar ou perder um dente permanente?

( ) Sim

( ) Não

18. Você já ouviu falar sobre alguma coisa que você pode colocar na boca para proteger seus dentes permanentes quando está praticando esporte?

( ) $\mathrm{Sim}$

( ) Não

Figura 1 - Questionário elaborado e validado por Castilho et al. (2009). (Parte II) 
fim, se qualquer indivíduo pode reimplantar esse dente. Destacar os meios de armazenamento, um possível auto-reimplante e sua ação imediata, foram as intenções da aplicação do jogo. Em relação ao que os alunos entendiam por trauma dental, houve um aumento de $12,5 \%$ entre os questionários respondidos antes e depois $(n=15)(37,5 \%)$. Sobre as atitudes a se tomar diante uma avulsão ocorreu um avanço de 7,5\% entre os questionários, ou seja, um maior número de alunos marcou a opção certa. Outra análise foi feita sobre os meios de armazenamento, onde os resultados diminuíram quanto ao soro fisiológico (de 12,5\% para 7,5\%). Já sobre os recipientes contendo leite, a porcentagem aumentou (de $47,5 \%$ para $65 \%$ ). Os dados obtidos pela revisão de literatura feita Poi et al. ${ }^{18}$, mostraram que a solução salina possui osmolaridade e pH compatíveis para a manutenção do ligamento periodontal e consequente sucesso do reimplante, no entando, não possui íons essenciais e glicose para que isso aconteça, sendo preferível a utilização de meios alternativos como o leite para a estocagem do dente.

O leite é um meio de escolha coveniente para estocagem dos dentes que sofreram avulsão devido a sua osmolaridade fisiológica e $\mathrm{pH}$ neutro, possuir nutrientes essenciais, e não ter componentes tóxicos ati-

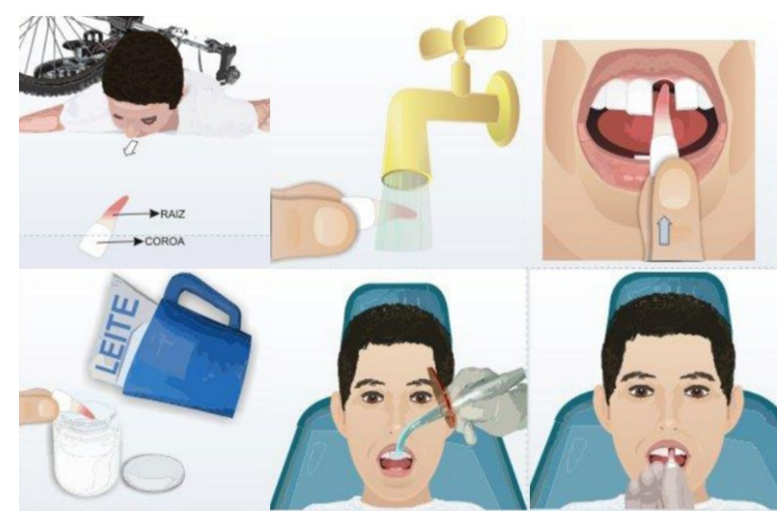

Figura 2- Jogo da memória com ilustrações sobre avulsão e reimplante dentário. (Ilustrações feitas por Paulo Sedlaceck, Araçatuba, SP).

Gráfico 1- Relação entre os questionários antes e depois do jogo, respectivamente, sobre a questão 11 .

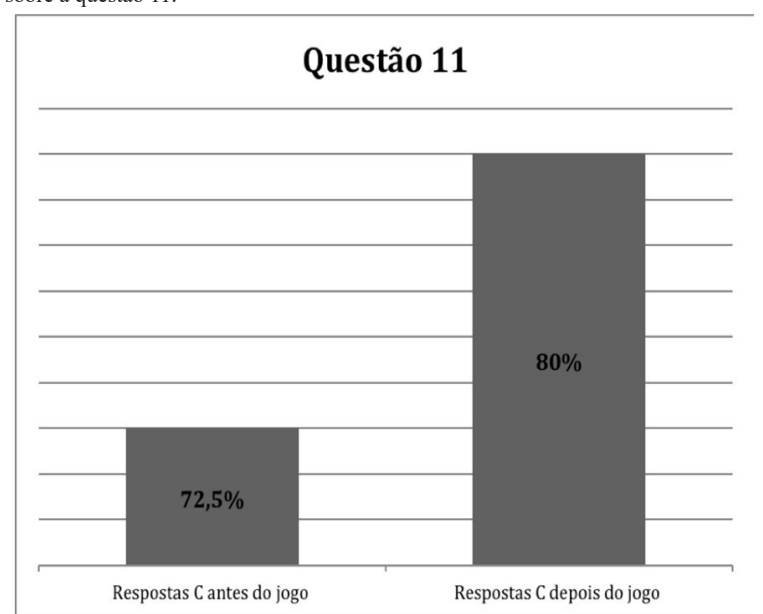

Gráfico 2- Relação entre os questionários antes e depois do jogo, respectivamente, sobre a questão 13 .

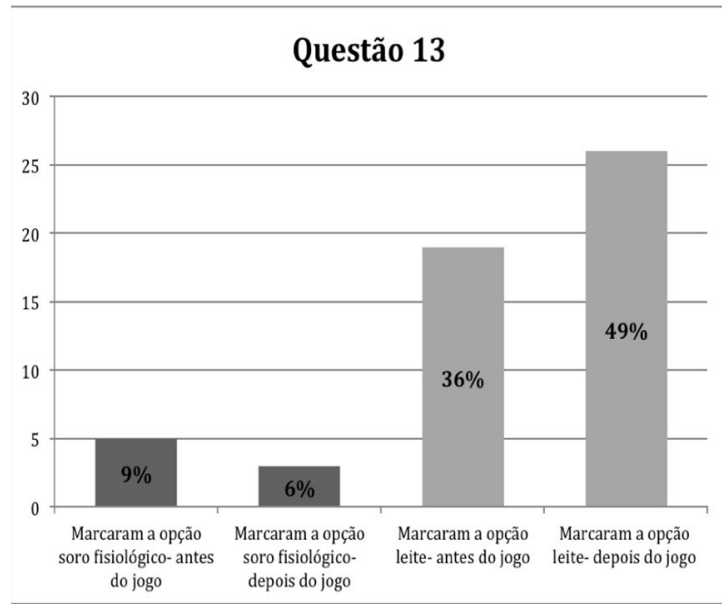

vos. ${ }^{6}$ Por isso a necessidade e conscientização das crianças sobre o meio de armazenamento do dente avulsionado. Com relação ao tempo máximo que o dente avulsionado pode permanecer fora da boca, também houve um aumento, oito alunos a mais marcaram a alternativa "imediatamente", quando se compara os dois questionários (de $25 \%$ para $45 \%$ ).

O reimplante imediado, ou mais precoce possível, aumenta a viabilidade celular em vários meios de armazenamento, como mostra o estudo de Moura et al. ${ }^{19}$, que fez essa análise em grupos de dentes que ficaram de 5 à 45 minutos fora do alvéolo. Apenas $2,5 \%(n=1)$ dos alunos marcaram a opção "qualquer pessoa" pode reimplantar dentes avulsionados, nos questionários aplicados antes do jogo da memória. Nos segundos questionários, houve um aumento de $30 \%(n=13)(32,5 \%)$.

Ainda que essas pesquisas possuam limites para entendimentos mais complexos, até um panfleto pode proporcionar informações básicas e aumentar o conhecimento dos alunos e das pessoas que os circundam, sobre avulsão e reimplante imediato. Em seu trabalho, Sedlacek ${ }^{20}$ usou como efeito educativo uma capa de caderno impresso com informação sobre avulsão e reimplante, para estudantes da sexta série do ensino fundamental. Os resultados da capa ilustrada aumentaram o conhecimento desses estudantes (de $n=39,36,1 \%$ para $n=7858,2 \%$ ), assim como o jogo da memória, que foi escolhido por ser uma alternativa animada e simples para lidar com crianças, já que eles precisam de situações que prendam sua atenção.

A disseminação do conhecimento entre estudantes jovens é fundamental para possibilitar um melhor prognóstico dos dentes reimplantados e prevenir, se possível, traumatismos dentários nesta população. Como citado por Ferrucio et al. $^{13}$, grande parte dos traumas dentais ocorrem nas escolas, principalmente durante atividades físicas ou recreativas, assim essa população, além de adquirir informações sobre o assunto, pode servir como multiplicadores do 
conhecimento para seus pais/responsáveis e professores.

Os resultados obtidos foram satisfatórios, mesmo com as dificuldades encontradas durante a aplicação da atividade educativa, como administrar o comportamento das crianças, o que pode ter interferido negativamente nos resultados. As estratégias de educação sobre trauma dental devem continuar nos ambientes escolares, pois é neste ambiente que podem ocorrer os acidentes durante as atividades recreativas e esportivas, ocasionando possíveis traumatismos dentários. Apesar de serem disseminados de forma mais simples aos estudantes, o conhecimento sobre avulsão e reimplante dentários pode ajudar na prevenção das sequelas do trauma e favorecer o prognóstico dos reimplantes dentários.

\section{Conclusão}

Uma das melhores formas de prevenção das sequelas do traumatismo dentário é a disseminação do conhecimento, e os resultados obtidos nesta pesquisa mostraram que as atividade com estudantes de 9 a 12 anos são necessárias, e permitiram aumentar o nível de conhecimento sobre avulsão e reimplantes dentários.

\section{Referências}

1. Petersen $P E$, Bourgeois $D$, Ogawa $H$, Estupinan-Day $S$, Ndiaye C. The global burden of oral diseases and risks to oral health. World Health Organ, 2005, 83:661-669.

2. Carvalho ES, Rosa RH, Pereira FM, Anbinder AL, Mello I Habitante SM, Raldi DP. Effects of diode laser irradiation and fibroblast growth factor on periodontal healing of replanted teeth after extended extra-oral dry time. Dent Traumatol. 2016 Nov 25; 33 (2), 91-99. doi:10.1111/edt.12308

3. Zaleckiene V, Peciuliene V1, Brukiene V, Drukteinis S.Traumatic dental injuries: etiology, prevalence and possible outcomes. Stomatologija. 2014;16(1):7-14.

4. Pavek DI, Radtke PK. Postreplantation management of avulsed teeth: an endodontic literature review. GenDent 2000 48:176-81.

5. Kaul R, Jain P, Angrish P, Saha S, Patra TK, Saha N, Mitra M. Knowledge, Awareness and Attitude towards Emergency Management of Dental Trauma among the Parents of Kolkata-An Institutional Study. Journal of Clinical and Diagnostic Research : JCDR. 2016;10(7):ZC95-ZC101.

6. Moazzami F, Asheghi B, Sahebi S. Effect of Four Different Media on Periodontal Ligament Cells Viability of Dry- Stored Dog Teeth. Journal of Dentistry. 2017;18(1):24-29.

7. Blomlöf, L. Milk and saliva as possible storage media for traumatically exarticulated teeth prior to replantation. Swed Dent J Suppl. 1981;8:1-26.

8. Sottovia AD, Sonoda CK, Poi WR, Panzarini SR, Lauris JRP Delayed tooth replantation after root surface treatment with sodium hypochlorite and sodium fluoride: histomorphometric analysis in rats. Journal of Applied Oral Science. 2006,14(2), 93-99.

9. Martins CM, Humanaka EF, Hoshida TY, Sell AM, Hidalgo MM, Silveira CS, Poi WR. Dragon's Blood Sap (Croton Lechleri) As Storage Medium For Avulsed Teeth: In Vitro Study Of Cell Viability. Braz. Dent. J. [online]. 2016, vol.27, n.6, pp.751-756.

10. Subramaniam P, Girija P, Eswara U, Girish Babu KL. Oral rehydration salt-liquid as a storage medium for avulsed tooth. Dent Traumatol. 2015, 31: 62-66. doi:10.1111/edt.12127

11. Najeeb S, Siddiqui F, Khurshid Z, Zohaib S, Zafar MS, Ansari SA. Effect of bisphosphonates on root resorption after tooth replantation - a systematic review. Dent Traumatol. 2017 Apr;33(2):77-83.

12. Andreasen JO, Andreasen FM. Textbook and colour atlas of traumatic injuries to the teeth, 4th edn. Oxford: BlackwellMunksgaard; 2007; 897p.

13. Ferrucio M, Sydney GB, Ferrucio E, Sydney RB. O papel da educação odontológica escolar na manutenção do elemento dental traumatizado. Rev ABO Nac. 2004, 11(1): 336-42.

14. Poi WR, Salineiro SL, Miziara FV, Miziara EV. A educação como forma de favorecer o prognóstico do reimplante dental. Revista da APCD. 1999, 53(6): 474-9.

15. Al-Asfour A, Anderson L, Al-Jame Q. School teacher's knowledge of tooh avulsion and dental fristain before and after receiving information about avulsed teeth and replantation. Dental Traumatol. 2008; 24:42-9.

16. Grewal N, Shangdiar GD, Samita G. Efficacy of a comprehensive dental education program regarding management of avulsed permanent teeth as a valid indicator of increased success rate of treatment of avulsion in a North Indian population. Contemporary Clinical Dentistry. 2015, 6(4):477-482.

17. Castilho LR, Sundefeld ML, de Andrade DF, Panzarini SR, Poi WR. Evaluation of sixth grade primary school crildren's knowledge about avulsionand dental reimplantation. Dent Traumatol. 2009, 25:429-32.

18. Poi WR, Sonoda CK, Martins CM, Melo ME, Pellizzer EP, Mendonça MR, Panzarini SR. Storage Media For Avulsed Teeth: A Literature Review. Brazilian Dental Journal. 2013, 24(5), 437-445.

19. Moura CCG, Soares PBF, Reis MVP, Fernandes Neto AJ, Soares CJ. Soy milk as a storage medium to preserve human fibroblast cell viability: an in vitro study. Brazilian Dental Journal. 2012, 23(5), 559-563.

20. Sedlacek, P. Efeito educativo de capa de caderno impressa com informações sobre avulsão e reimplantes dentários, em estudantes da sexta série do ensino fundamental. São Paulo [Dissertação- Mestrado na Área de Concentração em Clínica Integrada] - Faculdade de Odontologia de Araçatuba da UNESP; 2013 
Recebido em : 02/09/2017

Aprovado em: 21/09/2017

Os autores declaram que não há conflitos de interesse.

\section{Autor correspondente:}

Larissa Ribeiro Silva

Campus Universitário Darcy Ribeiro - UnB - Faculdade de Ciências da Saúde - Departamento de Odontologia 70910-900 - Asa Norte - Brasília - DF

E-mail: larissaribeiro2806@hotmail.com

Telefone: (61) 99614-9101

\title{
Knowledge evaluation of 9-12 years old students of the CEF GAN Asa Norte-DF on dental injuries after educational activity
}

\begin{abstract}
Dental trauma is among the major oral health disorders worldwide, along with caries and oral cancer. Among the injuries, dental avulsion is the most critical because it is the complete removal of the tooth socket and treatment success proves directly dependent on several factors, such as extra alveolar period, tooth storage and the type of replantation. The dissemination of knowledge among the target population is one of the ways to prevent dental trauma and minimize its consequences. Therefore, we evaluated the knowledge of dental avulsion and replantation of students aged 9-12 years through a questionnaire. Then, students participated in an educational activity (memory game) about the topic, and after, they answered the questionnaire again. It was observed that the students had more correct answer $(M=60.45, S D=14.92)$ after the educational activity in comparison with the first results obtained $(M=50.68, S D=11$, 06). The results obtained in this study showed that educational activities with students $9-12$ years of age are required and increases the level of knowledge about dental avulsion and replantation.
\end{abstract}

Keywords: Dental trauma; Tooth avulsion; Tooth replantation; Child; Questionnaires. 